\title{
ANATOMIA FOLIAR DE Pradosia lactescens (VELL.) RADLK. (SAPOTACEAE) OCORRENTE NA BAHIA
}

\author{
$\underline{E l i s a m a ~ d a ~ S i l v a ~ A l m e i d a ~}^{1}$ e Cláudia Elena Carneiro ${ }^{2}$ \\ 1. Bolsista PIBIC/FAPESB, Graduanda em Bacharelado em Ciências Biológicas, Universidade Estadual de Feira de Santana, e- \\ mail: almeidasama@gmail.com \\ 2. Orientadora, Laboratório de Micromorfologia Vegetal, Departamento de Ciências Biológicas, Universidade Estadual de Feira \\ de Santana, e-mail: carneiro@uefs.br
}

PALAVRAS-CHAVE: Flora; Taxonomia; Morfologia.

\section{INTRODUÇÃO}

O gênero Pradosia L. pertence à família Sapotaceae e está representado por 17 espécies no Brasil, com ocorrência também registrada para a Bahia (Carneiro et al., 2016), entretanto, devido a difícil delimitação de suas espécies, acredita-se que esse número não corresponde à realidade. Dentre as espécies que ocorrem na Bahia, Pradosia lactescens (Vell.) Radlk. é representada por árvores que alcançam até 15 metros de altura e são caracterizadas pelas flores com corola violácea, apresenta caulifloria e casca interna com sabor adocicado (Pennington, 1990). Alguns estudos de cunho ecológico, morfológico e molecular foram realizados para $P$. lactescens, no entanto, não há relatos de estudos anatômicos que forneçam dados estruturais das suas partes vegetativas. Assim, estudos morfológicos minuciosos poderão ser úteis para a taxonomia do grupo.

\section{METODOLOGIA}

Foram coletadas três folhas adultas e saudáveis de três indivíduos da espécie estudada. As amostras foram submetidas aos processos de reidratação e distensão das células com água destilada e gotas de glicerina a $50 \%$ e $\mathrm{KOH}$ a $2 \%$, respectivamente, e armazenadas em frascos contendo etanol a 70\% (Kraus \& Arduin, 1997). Para a análise da estrutura interna, forma feitos cortes transversais à mão livre do pecíolo e da lâmina foliar, os quais foram clarificados com hipoclorito de sódio a $10 \%$ e corados com azul de astra a $1 \%$ e safranina a $1 \%$ na proporção de 9V:1V, respectivamente (Kraus \& Arduin, 1997; Johansen, 1940). Para a obtenção da epiderme foliar foram utilizadas, a priori, a metodologia de dissociação de Jeffrey (Macêdo, 1997), utilizando a safranina aquosa a 1\% para a coloração (Johansen, 1940). Porém, para alguns espécimes o método não foi eficaz, sendo utilizada a metodologia de Foster (Macêdo, 1997). Logo após o processamento das amostras, lâminas semipermanentes foram confeccionadas com os cortes transversais e com a epiderme, utilizando como meio de montagem glicerina a $50 \%$ e gelatina glicerinada, sendo as lâminas semipermanentes lutadas com esmalte incolor e parafina, respectivamente. Testes histoquímicos foram realizados a fim de verificar a presença de algumas substâncias ergásticas produzidas pelas espécies, e para isso os reagentes utilizados foram: cloreto férrico, para identificar compostos fenólicos (tanino); lugol, para detecção de amido e floroglucina, que identifica a presença de lignina (Macêdo, 1997).

Posterior à montagem das lâminas, a análise foi realizada em microscopia de luz. Todas as amostras analisadas foram descritas utilizando os termos específicos usuais em estudos micromorfológicos, e fotomicrografadas. 


\section{RESULTADOS E DISCUSSÃO}

Em vista frontal Pradosia lactescens apresentou folha hipoestomática, com estômatos anisocíticos e tricomas malpighiáceos ocorrendo apenas nas regiões de nervuras central e secundárias da face abaxial. As células epidérmicas possuem paredes anticlinais sinuosas de formato retangular na face adaxial e irregular na superfície abaxial (Figura A).

Em secção transversal, a epiderme é unisseriada, o mesofilo é dorsiventral composto por uma camada de parênquima paliçádico e vários estratos de parênquima lacunoso. Ocorrem fibras esclerenquimáticas formando faixas de sustentação da lâmina foliar, ocorrendo associadas ou não aos feixes vasculares secundários (Figura B.1). As folhas de $P$. lactescens apresentam parênquima aquífero próximo à nervura central (Figuras B.3), a qual apresenta feixe vascular em forma de meia-lua envolto por uma faixa de fibras de esclerênquima e laticíferos associados. $\mathrm{O}$ bordo é fortemente fletido com cutícula formando flanges, parênquimas paliçádico e lacunoso interrompidos por feixes de fibras esclerenquimatosas e células de colênquima na extremidade do bordo (Figura B.4). A cutícula forma flanges e apresenta estrias. O pecíolo apresenta variação morfológica em sua extensão, passando de um formato de coração na extremidade mais próxima ao ramo, à forma de ferradura na extremidade que se conecta com a base da folha (Figura C). Apresenta epiderme unisseriada e cutícula espessa, três a quatro extratos de colênquima na região cortical e laticíferos distribuídos esparsamente pelo córtex; a nervura central tem forma de meia lua circundada por faixas de esclerênquima.
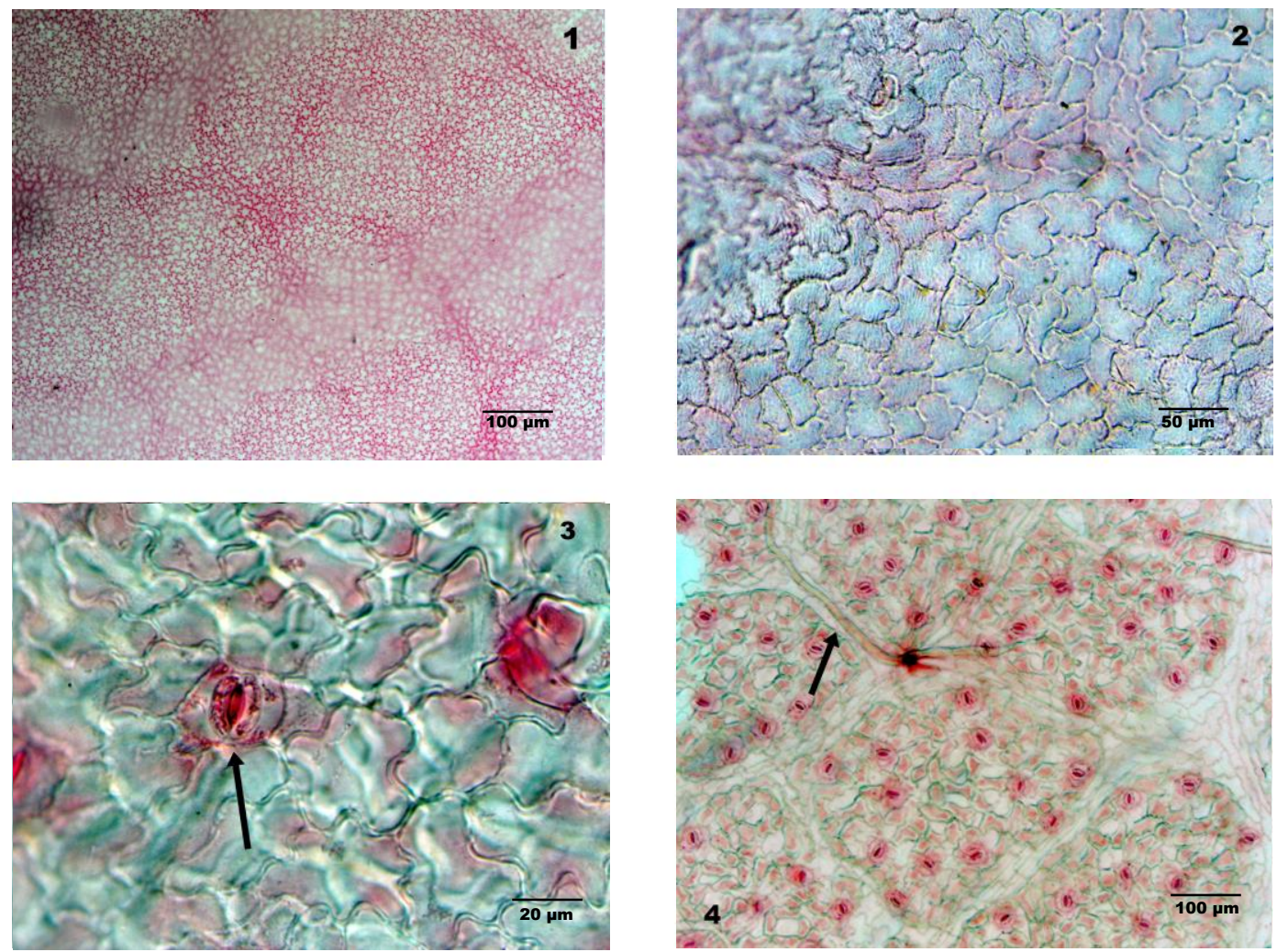

Figura A. Epiderme de Pradosia lactescens (Vell.) Radlk. em vista frontal. 1. Superfície adaxial. 2. Células costais e intercostais da face adaxial. 3. Superfície abaxial com estômatos anisocíticos (seta). 4. Superfície abaxial com tricomas malpighiáceos (seta). 

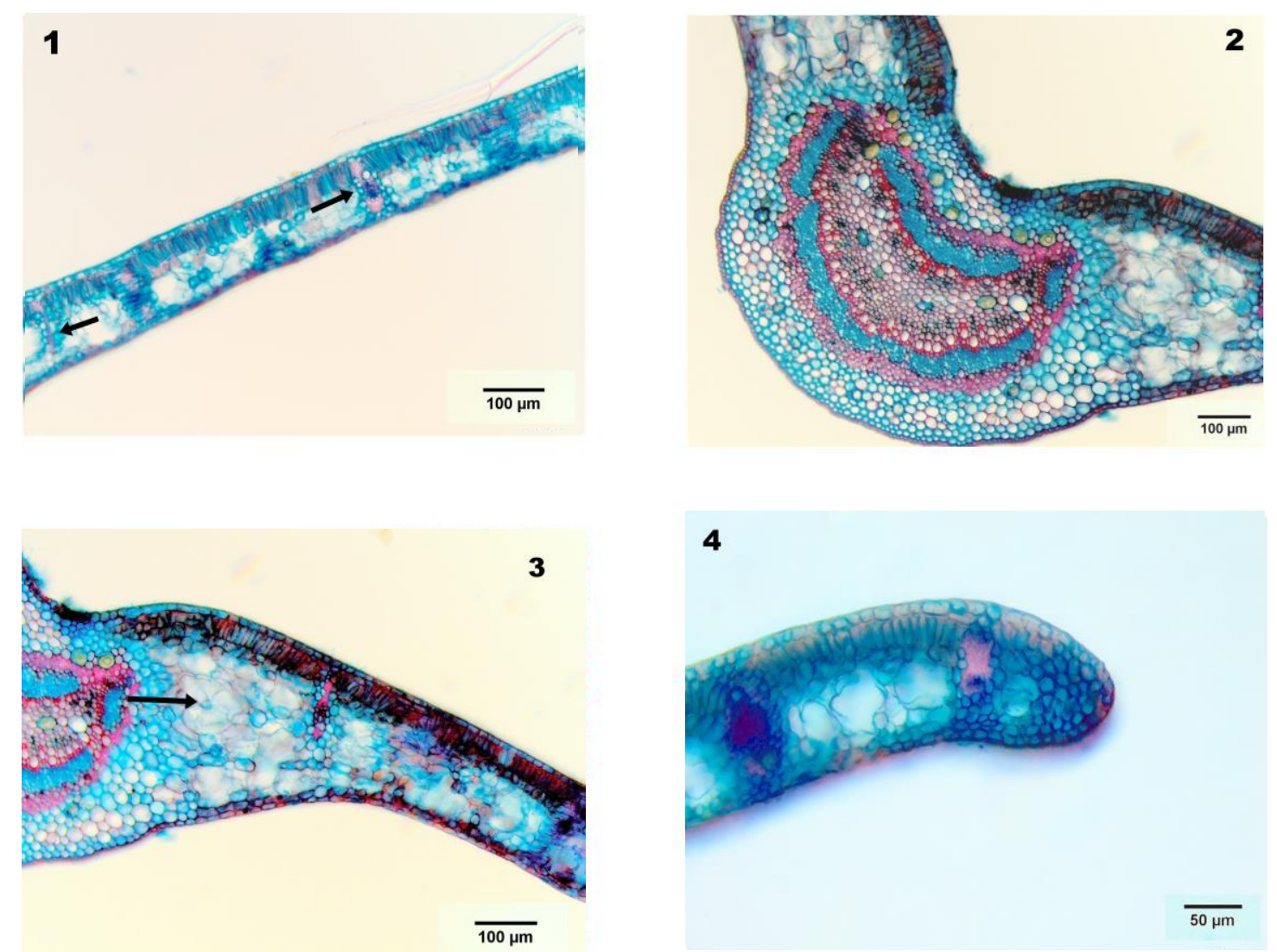

Figura B. Pradosia lactescens (Vell.) Radlk. em secção transversal. 1. Mesofilo dorsiventral contendo fibras de esclerênquima formando faixas de sustentação (setas). 2. Arranjo do cilindro vascular central. 3. Detalhe: Células de parênquima aquífero próximas à nervura central (seta). 4. Vista lateral do bordo fortemente fletido de P. lactescens.
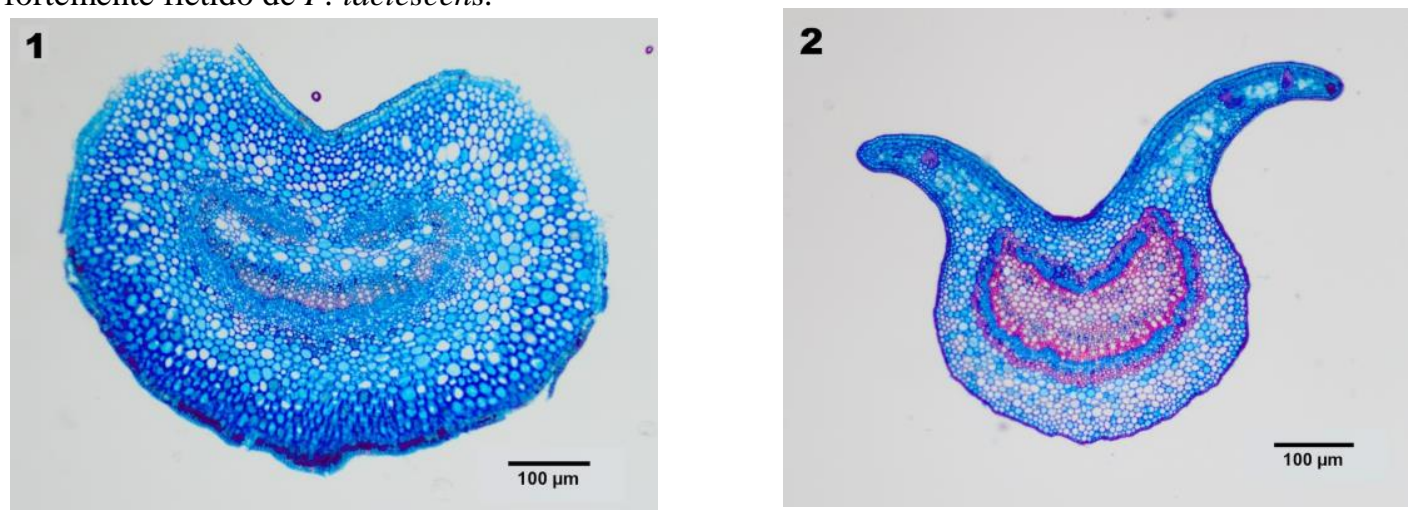

Figura C. Seç̧ão transversal do pecíolo de Pradosia lactescens (Vell.) Radlk. 1. Região mais próxima ao ramo. 2. Região próxima à base da folha.

Os testes histoquímicos apresentaram resultados positivos para: amido (lugol) nos laticíferos e no mesofilo; tanino (cloreto férrico) na região da nervura central e também no mesofilo; e lignina (floroglucina) também na região da nervura central, pecíolo e nos feixes vasculares.

Grande parte das características observadas está de acordo com Solereder (1908) e Metcalfe \& Chalk (1950) para a família Sapotaceae, tais como mesofilo dorsiventral, a presença 
de laticíferos e tricomas malpighiáceos. Algumas particularidades encontradas como a presença de células de armazenamento de água, as faixas de fibras esclerenquimáticas inseridas no mesofilo e a cutícula espessa e altamente estriada, podem ser interpretadas como uma adaptação ao meio, neste caso, regiões que são expostas a grandes períodos de seca e forte luminosidade, como melhor forma de evitar perda de água e retê-la dentro destas condições, não prejudicando o metabolismo do corpo vegetal (Dickison, 2000). A sinuosidade das paredes anticlinais na epiderme, que é atribuída aos grupos ocorrentes em ambientes úmidos, mas, de acordo com Arruda \& Neves (2005), também pode conferir resistência mecânica à epiderme em épocas de escassez hídrica. Já as variações morfológicas no pecíolo podem ser tratadas como caráter taxonômico próprio da espécie.

\section{CONSIDERAÇÕES FINAIS}

Este estudo contribuiu com informações para o grupo, porém ainda carece de estudos micromorfológicos complementares, como, por exemplo, análise da superfície foliar em microscopia eletrônica de varredura (MEV), que está previsto para a próxima etapa de estudos para a espécie, juntamente com os estudos anatômicos das outras espécies pertencentes ao gênero para posteriores estudos comparativos entre os táxons.

\section{REFERÊNCIAS}

ARRUDA, Rosani do Carmo de Oliveira, and Lea de Jesus Neves. Leaf anatomy of Trilepis lhotzkiana Nees and Trilepis ciliatifolia T. Koyama (Cyperaceae) Juss. Acta Botanica Brasilica 19.4 (2005): 889-897.

CARNEIRO, C.E.; ALVES-ARAUJO, A.; ALMEIDA Jr., E.B. Sapotaceae. In: Lista de Espécies da Flora do Brasil. Jardim Botânico do Rio de Janeiro. (http://floradobrasil.jbrj.gov.br/jabot/floradobrasil/FB217). Acesso: 20 set 2016.

DICKISON, D.C. 2000. Integrative Plant Anatomy. San Diego: Harcourt Academic Press, p. 295-311.

JOHANSEN, D.A. 1940. Plant Microtechnique. New York, Mc Graw Hill Book, 523p.

KRAUS, J.E. \& ARDUIN, M. 1997. Manual básico de métodos em morfologia vegetal. Rio de Janeiro, EDUR, Seropédica, 198p.

MACÊDO, N.A. 1997. Manual de Técnicas em Histologia Vegetal. Feira de Santana, Universidade Estadual de Feira de Santana, 60p.

PENNINGTON, T.D. 1990. Sapotaceae. In: Flora Neotropica, New York, v. 52, 770p.

SOLEREDER, H. 1908. Systematic anatomy of the dicotyledons. Oxford, University Press. 